\title{
Identidade local e imaginário urbano no telejornalismo: \\ Os 159 anos de Juiz de Fora no MGTV
}

\author{
Francisco Angelo Brinati* \\ Paulo Roberto Figueira Leal**
}

Resumo: Parte-se aqui da hipótese de que o telejornalismo local, por seu alcance e cotidianidade, atua como (re)produtor privilegiado de narrativas constituintes do imaginário urbano de uma cidade sobre si mesma, produzindo efeitos identitários. O presente artigo busca avaliar como isso se dá num caso concreto, por meio da análise das ênfases discursivas, pelo MGTV $1^{a}$ e $2^{a}$ edições da TV Panorama (afiliada Rede Globo), na cobertura jornalística da comemoração dos 159 anos do município de Juiz de Fora. Discute-se qual foi a representação da cidade efetivada na série especial comemorativa. Supõe-se que identidades não são fenômenos naturais ou essenciais, mas sim construções simbólicas e discursivas a gerarem sentimento de pertencimento - o que leva os meios de comunicação a serem vocalizadores preferenciais destes discursos.

Palavras-chave: Identidade; telejornalismo; imaginário urbano.

\section{Local identity and urban imaginary in TV news: The 159 years of Juiz de Fora in the MGTV}

Artigo recebido em: $1^{\circ}$ de setembro de 2010 Aprovado em:

28 de setembro de 2010

\section{* Mestrando em} Comunicação e Sociedade pela FACOM - UFJF.

chicobrinati@yahoo.com.br

** Doutor e mestre em Ciência Política (luperi). Professor do mestrado em Comunicação da FACOM-UFJF.

pabeto.figueira@uol.com.br

\begin{abstract}
It starts here with the hypothesis that the local TV journalism, for its scope and everyday acts such as (re) producer of narratives privileged constituents of urban imagination of a city on itself, producing identity effects. This article aims to assess how it happens in a particular case, through the analysis of the emphases discursive at MGTV 1st and 2nd editions of TV Panorama (affiliated Rede Globo), the coverage of the commemoration of 159 years in the municipality of Juiz de Fora . It discusses what was the effect the representation of the city special commemorative series. It is assumed that identities are not essential or natural phenomena, but rather symbolic and discursive constructions to generate the feeling of belonging - which carries the media to be vocalized these preferred discourses.
\end{abstract}

Keywords: Identity; telejournalism; urban imaginary. 


\section{Introdução}

TCal primário de pertencimento, a cidade constitui espaço de trocas culturais, sociais e políticas: trata-se, portanto, de um objeto primordial para os debates relativos à constituição identitária - dela própria e de seus moradores. Identidades, nessa perspectiva, não são fenômenos naturais, essenciais ou materiais - ao contrário, devem ser entendidas como narrativas derivadas do imaginário e da memória sociais e de disputas de poder (afinal, das muitas narrativas possíveis sobre a cidade, algumas vêm à tona e outras ficam eclipsadas).

As identidades não são nunca unificadas; que elas são, na modernidade tardia, cada vez mais fragmentadas e fraturadas; que elas não são, nunca, singulares, mas multiplamente construídas ao longo de discursos, práticas e posições que podem se cruzar ou ser antagônicas. As identidades estão sujeitas a uma historicização radical, estando constantemente em processo de mudança e transformação. (HALL, 2000, p.108).

As evidências desses deslocamentos históricos das identidades são numerosas. De acordo com Woodward (2000), a contemporaneidade vem assistindo a uma intensificação, num contexto de globalização, dos processos de reconstruções das identidades nacionais e étnicas - cenário marcado também pela emergência dos novos movimentos sociais, preocupados com a reafirmação das identidades pessoais e culturais. Esses processos colocam em questão uma série de certezas tradicionais, dando força ao argumento de que existe hoje uma crise da identidade.

Também as identidades de uma cidade - que sempre foram social e historicamente constituídas e reconstituídas - estariam agora em acelerada mutação, neste ambiente caracterizado pelo contato com a diversidade que designa a experiência contemporânea. Ainda segundo Woodward, "os processos históricos que, aparentemente, sustentavam a fixação de certas identidades estão entrando em colapso e novas identidades estão sendo forjadas, muitas vezes por meio da luta e da contestação política" (WOODWARD, 2000, p. 39).

A cidade contemporânea, influenciada pelos efeitos do mundo globalizado, constrói suas particularidades locais a partir de uma mescla das demarcações baseadas no imaginário e no cotidiano de seus moradores com as experiências das pessoas (ou, quando não pessoal e presencialmente, das informações) que vêm de fora, que acrescentam elementos exteriores à cultura local. Neste jogo de amálgamas entre dentro e fora, interior e exterior, identidade e alteridade, forjam-se os deslocamentos que explicitam as transformações identitárias na cidade:

A cidade se constitui como exterioridade, como exposição, acolhendo estrangeiros, fazendo - mesmo para os que estão em casa - desse estrangeirismo um devir. Há uma constante mobilização, que é em parte física, mas envolve uma 
transformação mais forte, um investimento na diferença e na singularização. Gera-se uma inquietude, característica dos meios urbanos, que nos faz desejar ir além do reconhecimento das pequenas vizinhanças, sair à rua, experimentar novos lugares e enfrentar os riscos do imprevisível. (...) Nas cidades se gera um poderoso espaço de exterioridade, em contraste com o interior dos espaços fechados dos meios familiares e provincianos. Um espaço que precisamente recebe esses estranhos, egressos de fora, mas também da própria cidade, uma vez que ela se constitui como exterior. A diversidade tende a produzir todos como estranhos e deveríamos entender "espaço de exterioridade", em toda a radicalidade do termo, como um espaço feito de fora. (CAIAFA, 2007, p.119).

A descrição das cidades vai além da geografia dos mapas e da história oficial evocada em seus patrimônios e monumentos. Produz-se a partir de discursividades e produções simbólicas que atribuem a ela determinados sentidos - que podem se manifestar em palavras, sons ou imagens carregadas de significados. Essas escolhas sempre implicam disputa: na narrativa sobre a cidade, o que deve ser explicitado e sobre que se deve silenciar?

Dado que qualquer cidade é múltipla (em suas distintas realidades urbanas e sociais, refletidas numa miríade de específicas memórias, linguagens e representações particulares dos diversos grupos ou indivíduos que a constituem), a determinação de quais serão as narrativas hegemônicas sobre o sentido preferencial daquele lugar assentam-se em relações de poder simbólico. Como determinada significação se impõe sobre outra? A mídia

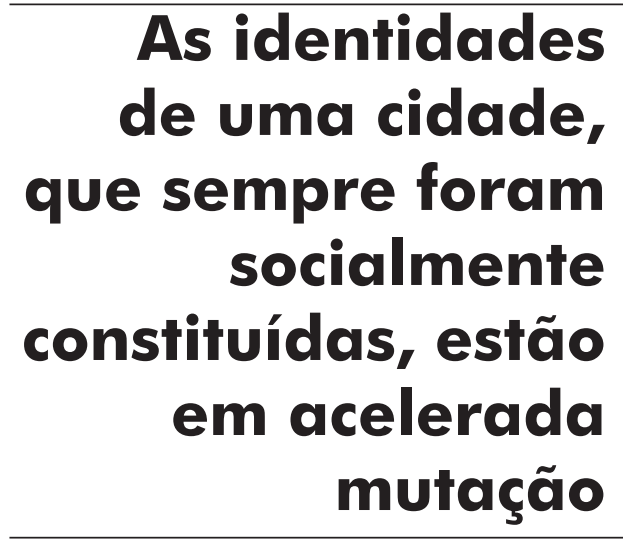
surge, então, como elemento de extrema importância na determinação de quais representações da cidade, em detrimento de outras, tendem a prevalecer. A partir de certas recorrências nos enquadramentos discursivos sobre a cidade, projeta-se uma narrativa preferencial que, frequentemente, acaba por tornar-se o discurso oficial da cidade sobre si mesma e passa a ser tomado como a "realidade" daquela localidade.

\section{Mídia e identidade local}

$\mathrm{Na}$ perspectiva da tradição sociológica do Interacionismo Simbólico, a percepção da realidade que os indivíduos têm é sempre influenciada pelos códigos apreendidos durante os processos de socialização - ou seja, os discursos presentes nas interações sociais acabam por designar algumas chaves de leitura preferenciais sobre a realidade. Diante da presença cotidiana dos meios de comunicação de massa na vida da maioria dos cidadãos, as narrativas que por lá circulam adquirem relevância (bem como os silêncios que produzem) na determinação dos sentidos socialmente atribuídos, por exemplo, a uma cidade.

É sempre no espaço social compartilhado que determinadas leituras do mun- 
do se impõem a outras - logo, identidades (de indivíduos, grupos ou espaços geográficos) também devem ser assim explicadas. Segundo Berger e Luckmann, "a identidade é evidentemente um elemento-chave da realidade subjetiva e, tal como toda realidade subjetiva, acha-se em relação dialética com a sociedade" (BERGER e LUCKMANN, 1995, p. 228). Deste modo, aquilo que historicamente se consolidou como a identidade de uma cidade é, em grande medida, construído pelos filtros e escolhas recorrentes feitas pelos meios de comunicação ao falar dela. Se identidades são discursos que supostamente se ancoram na realidade, e se a mídia tem um papel central nas mediações que levam grupos sociais a reconhecerem em sua produção um relato desta realidade, é inevitável deduzir que as narrativas que circulam predominantemente nos veículos de comunicação tendem a assumir posição de destaque frente a outras.

No Brasil, a televisão é a mídia de maior alcance - mais de $98 \%$ dos lares brasileiros são por ela atingidos. A Rede Globo de Televisão é a emissora brasileira que detém os maiores índices de audiência e as maiores fatias do mercado publicitário. As suas afiliadas, instaladas país afora, retransmitem, durante quase todos os horários, a programação nacional, abrindo poucos espaços para a produção regional ou local. Mas mesmo escassos, estes programas locais costumam ser líderes da audiência televisiva.

No caso da TV Panorama, afiliada na Zona da Mata e Campo das Vertentes de Minas Gerais (região onde a Globo possui afiliada desde abril de 1980, com cobertura em cerca de 120 municípios mineiros, uma área que abrange, aproximadamente, dois milhões de habitantes), apenas os telejornais MG Notícia, MGTV $1^{a}$ edição e $2^{a}$ edição, além do programa Panorama Entrevista, são produções regionais ${ }^{1}$.

Todos eles são líderes de audiência em seus horários². Como os programas produzidos pela emissora regional abordam o cotidiano da cidade, é factível supor que tenham alguma relevância na consolidação da identidade local, a partir da oferta sistemática de representações simbólicas que adensem a proximidade com o público:

Se o jornalismo de TV é um importante espaço na construção de sentidos do nacional, acreditamos que o telejornal local funcione como fator determinante para a (re)construção de uma cultura do local, do resgate às raízes, para a criação de vínculos entre público e emissora. (COUTINHO e MARTINS, 2008, p.5).

\footnotetext{
- O MG Notícia é exibido de segunda a sexta-feira, às $08 \mathrm{~h}$, com cinco minutos de produção. Já o MGTV $7^{a}$ edição vai ao ar por volta de 12h15, com média de 27 minutos de produção, de segunda a sexta. Aos sábados, ele começa às 11 h58 e tem produção de 48 minutos, em média. O MGTV $2^{a}$ edição tem início geralmente às 19h10, com produção de aproximadamente 13 minutos, de segunda a sábado. O quarto programa regional é o Panorama Entrevista, exibido aos domingos, no horário de 23h45, com 36 minutos de produção. Além destes programas, são apresentados flashes de um minuto de produção, durante a programação, o Panorama Cidade.

${ }^{2}$ MG Notícia: Audiência: 14 Ptos - Share: 60\% SHR / Emissora B: Audiência: 2 Ptos - Share: 6\% SHR; MGTV $7^{a}$ Edição: Audiência: 22 Ptos - Share: 61\% SHR / Emissora B: Audiência: 7 Ptos - Share: 18\% SHR; MGTV 2a Edição: Audiência: 40 Ptos - Share: 71\% SHR / Emissora B: Audiência: 3 Ptos Share: 5\% SHR; Panorama Entrevista: Audiência: 14 Ptos - Share: 46\% SHR / Emissora B: Audiência: 1 Pto - Share: 2\% SHR; Fonte: Ibope/Media Quiz - Mercado Juiz de Fora - Dados domiciliares novembro/08
} 
Os telejornais locais, então, são mediadores entre telespectadores e cidade, já que os indivíduos veem a maioria dos acontecimentos que fazem parte do seu cotidiano por meio da TV, mesmo que os fatos mostrados apresentem discursos parciais. Ao fazê-lo, os veículos consolidam determinadas representações da cidade que, mais facilmente que outras, tendem a se tornar dominantes.

As rotinas produtivas estabelecidas pela mídia contribuem para a construção de representações sociais, pois além de realizarem uma intermediação entre realidades, oferecem também uma interpretação sobre determinado fato e/ou acontecimento, apesar dos discursos de imparcialidade. Além disso, também efetua a divulgação de representações existentes. Ao utilizar uma imagem em detrimento de outra, ao privilegiar uma fonte de informação, escolhas vão sendo feitas e é justamente este procedimento que irá culminar na apresentação de um fragmento do real. (SILVA, 2005, p. 2).

São, portanto, veículos fundamentais na construção dessa realidade. Por meio dos discursos adotados por eles, os sujeitos veem-se diante de discursos que referendam ou modificam as projeções identitárias das localidades em que vivem. Com isso, podem emergir dos discursos midiáticos e das relações sociais dela decorrentes novas identidades. Em outras palavras, discursos não são apenas reflexos da realidade: eles criam realidade.

Assim, a cultura é correlata de determinados campos de saber (Sociologia, Antropologia...), cuja operacionalidade se dá através de redes discursivas, ou seja, de formações discursivas que inventam as categorias das quais se ocupam. Podese dizer que o discurso cria os referentes que possibilitam operar com a "realidade" sem tomá-la como representação, mas marcadores em relação aos quais os sujeitos passam a reconhecer-se ou diferir-se. (GUARESCHI, 2006, p. 83).

No caso da cobertura midiática das cidades, há momentos preferenciais nos quais os macro-sentidos daquele lugar são explicitamente evocados (porque implicitamente o são todo o tempo). Geralmente perto das comemorações dos aniversários de fundação ou emancipação dos municípios, os meios de comunicação fazem matérias especiais sobre o assunto, de onde emergem as narrativas mais consolidadas. Segundo Musse, "considerando os meios de comunicação como mediadores nas relações do sujeito com o seu entorno, observaremos que a imprensa tem um papel capital na construção do imaginário da cidade" (MUSSE, 2008, p. 52).

O município de Juiz de Fora não é exceção. Situado na divisa com o Estado do Rio de Janeiro - e fonte de vários estudos sobre o que chamamos de "crise identitária", como o realizado por Musse (2008) -, é conhecido por ter uma identidade marcada pelo sentimento fronteiriço (em que se é algo e sua alteridade ao mesmo tempo). De que modo estas dimensões discursivas 
são mobilizadas nos momentos comemorativos em que a cidade olha para si mesma? Que narrativas são mobilizadas para dar conta de sua especificidade identitária?

Portanto, pretende-se aqui analisar as matérias especiais de aniversário, veiculadas entre os dias 28 e 30 de maio de 2009 , nos programas televisivos locais de maior audiência: os telejornais MGTV $1^{\mathrm{a}}$ e $2^{\mathrm{a}}$ edições, na série intitulada "JF: 159 anos", da TV Panorama. Como elas retrataram a identidade da cidade e dos juizforanos e a que narrativas prioritárias se remeteram? É o que discutese a seguir.

\section{A série "JF: 159 ANOS"}

No dia 31 de maio de 2009, a cidade de Juiz de Fora-MG completou 159 anos de emancipação. A TV Panorama, então, produziu uma série especial de quatro reportagens sobre o município, veiculadas nos dois principais telejornais diários da emissora, na semana anterior ao aniversário.

Logo na primeira reportagem da série (com três minutos e 50 segundos de produção), veiculada no MGTV $1^{a}$ edição do dia 28 de maio, quinta-feira, a crise de identidade do juizforano foi abordada no paradoxo de estar em Minas Gerais, mas sentir-se próximo do Rio de Janeiro: "Carioca do brejo... Mineiro às avessas... Afinal, quem é o juizforano?” (MGTV 1ª edição, 28/05/2009). O habitante de Juiz de Fora era representado na matéria como um misto do "cidadão tranquilo", bem mineiro, tradicionalista e o que tem como espelho o cosmopolita Rio de Janeiro:

Afinal de contas, quem é o juizforano? O mineiro tradicionalista ou aquele que sonha em ser carioca? Segundo os especialistas, nem uma coisa e nem outra. O filho da Princesa de Minas é o sujeito com uma identidade própria definida ao longo dos seus 159 anos de história (MGTV $1^{\mathrm{a}}$ edição, 28/05/2009).

De acordo com a matéria, uma identidade própria que transita entre a tradição e a modernidade. "Nem tão cosmopolita, nem tão tolinho da aldeia", segundo uma entrevistada. A matéria fez uma análise visual do juizforano, com base na moda típica da cidade - segundo o texto, seria possível defini-la como uma mistura de estilos, um mix entre o tradicional e o moderno. A ideia da mistura apareceu ao longo de toda a reportagem, como vemos no trecho: "Há uma explicação histórica para o comportamento do juizforano. A cidade se formou ao longo do Caminho Novo, com um olhar de vanguarda" (MGTV $1^{\text {a }}$ edição, 28/05/2009).

Ou seja, mesmo fazendo menção explícita à recusa dos dois polos que representariam os modelos prototípicos (tradicional ou moderno), definia-se a juizforaneidade a partir de um ponto médio unificador - pressupondo-se, em certo sentido, que todos os juizforanos pudessem enquadrar-se nele e não evidenciando a possibilidade de que existissem indivíduos ou grupos capazes de serem efetivamente tradicionais ou modernos. A presença de um sentido 
majoritário para a juizforaneidade se impunha discursivamente na matéria, silenciando sobre a real diversidade existente em Juiz de Fora ou em qualquer outro lugar.

A segunda reportagem foi ao ar no MGTV $1^{\text {a }}$ edição de sexta-feira, dia 29 de maio. Tendo também a identidade como tema, mas desta vez a da cidade. Uma breve passagem pelas fases marcantes da história do município, em que ele foi referência no estado ou no país. Essas fases, geralmente, receberam, por analogia, nomes de outras cidades, o que a reportagem chamou de "apelidos”.

$\mathrm{Na}$ matéria intitulada "Uma cidade com muitos nomes", um personagem que mostrava o eldorado industrial no início do período republicano abria a reportagem, com imagens de chaminés de fábricas. Citava-se Marmelos, primeira usina hidrelétrica da América Latina, um dos símbolos do pioneirismo da cidade, para explicar o apelido de "Manchester Mineira, referência à cidade inglesa, um dos berços do industrialismo", segundo o texto.

O segundo apelido era o de Atenas Mineira, por ser um polo que projetou artistas de teatro, música, literatura e artes plásticas. Citavam-se os escritores juizforanos Pedro Nava e Murilo Mendes. Ainda segundo o texto: “O progresso da Manchester e a riqueza cultural da Atenas convivem em harmonia. E, por que não, um terceiro apelido? A vanguarda... Principalmente na arquitetura... Influenciada por diversos estilos cria a comparação com a cidade espanhola de Barcelona” (MGTV $1^{\text {a }}$ edição, 29/05/2009).

A matéria lembrava ainda que o município passou a ser conhecido como a cidade dos estudantes. E, no período mais recente, com os escândalos políticos, o texto fazia menção à fictícia cidade de Pasárgada: "Seu mais recente apelido, entretanto, não é lá motivo de orgulho ${ }^{3 ”}$. A matéria teve três minutos e 57 segundos de produção.

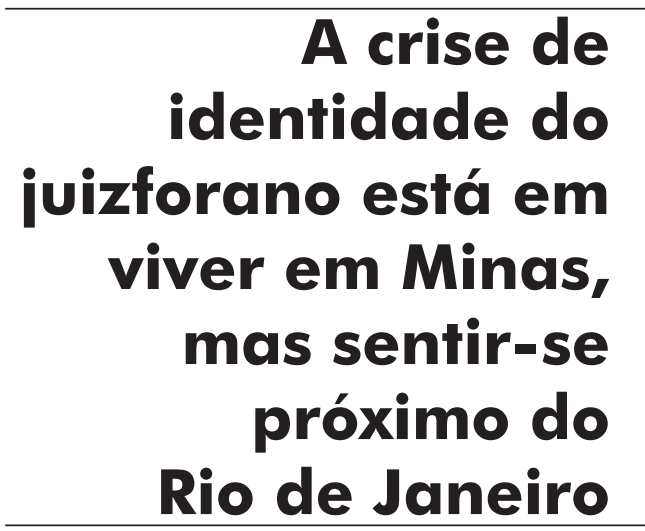

Além de ilustrar um fenômeno evidenciador do caráter discursivo e simbólico das identidades - eles não são perenes, mudam com o tempo -, a matéria ilustrava subtextualmente um fenômeno metalinguístico: ao mesmo tempo em que discorria sobre os apelidos de Juiz de Fora em perspectiva histórica, falava (mesmo que não se desse conta disso) do papel que os meios de comunicação desempenharam na própria consolidação e socialização desses apelidos. A “Manchester”, a “Atenas” e a "Barcelona” só passaram a ser referências identitárias para Juiz de Fora quando publicizadas pelos meios de comunicação ao longo das décadas.

\footnotetext{
3 Pasárgada, o poema de Manuel Bandeira que serviu de inspiração para batizar a operação da Polícia Federal que prendeu cerca de dezesseis prefeitos no dia 09 de abril de 2008, descreve uma cidade paradisíaca onde tudo se pode por ser amigo do rei - "vou-me embora pra Pasárgada, lá sou amigo do rei" - no caso da operação, um juiz que supostamente vendia sentenças para facilitar a liberação irregular de verbas para as cidades. Os envolvidos foram acusados de desviar R\$200 milhões dos cofres públicos, que deveriam ser destinados, principalmente, à saúde e à educação. Após oito meses de investigação, foram presos em torno de 50 pessoas entre magistrados, prefeitos, advogados, procuradores municipais, assessores e lobistas. Entre eles, o então prefeito de Juiz de Fora, Alberto Bejani, que permaneceu 13 dias preso na penitenciária Nelson Hungria, na cidade de Contagem - MG
} 
Podemos concluir que o espaço urbano é construído, hoje, especialmente pela mídia, fazendo com que a relação das cidades com seus habitantes seja, em alguns casos, mediada e, em outros, midiatizada, chegando ao paroxismo em que não se consegue mais distinguir a cidade real da cidade simulada. (MUSSE, 2008, p. 56)

Ao ressaltar o pioneirismo pela ideia mítica da "Manchester Mineira", tratada como um capítulo de orgulho pela maioria dos juizforanos até hoje, a matéria estabelecia um contraditório com a fase atual, "Pasárgada", motivo de vergonha. É interessante notar que há aí uma evidenciação de como a memória nunca é um relato objetivo do passado.

Nas entrelinhas, apresenta-se o discurso subliminar de que, no passado, não teriam existido graves problemas (há silêncio sobre isso) e que a realidade atual da cidade seria marcada apenas por eles, sem nenhum motivo para comemorar. Mesmo resgatando uma identidade de pioneirismo, de vanguarda da cidade, o tema não é o passado, mas o presente: a verdadeira discussão é aquela relativa à decadência do município. $\mathrm{O}$ imaginário presente sobre a cidade dialoga com o passado de maneira tão idealizada - como se fosse possível voltar aos tempos áureos da Manchester - apenas para fugir da realidade e negar o presente.

A terceira matéria, veiculada no MGTV $1^{\text {a }}$ edição de sábado, 30 de maio, véspera do aniversário de Juiz de Fora, insistia na questão do perfil do juizforano. O telejornal foi especial, todo ancorado do parque do Museu Mariano Procópio, um dos cartões postais da cidade. A matéria especial teve nove minutos de produção.

A particularidade desta terceira reportagem é que ela analisou a contribuição de grupos étnicos específicos que foram relevantes para a constituição da cidade: africanos, alemães, italianos, portugueses, sírios e libaneses: "Seriam eles os responsáveis pela nossa identidade? Nós fomos em busca destas raízes” (MGTV 1ª edição, 30/05/2009).

Ainda segundo a matéria: "Parabéns, Juiz de Fora! A cidade de várias cidades... Nasceu cosmopolita... Viveu de influências diversas... Culturas várias... Hábitos outros tantos! Mas soube aproveitar de cada forasteiro! A ser única entre todos...” (MGTV $1^{\text {a }}$ edição, 30/05/2009). O tom adotado é o de que, aqueles grupos que foram diversos e estavam fora, num dado momento passam a constituir o novo. Como sugere Bhabha,

Os embates de fronteira acerca da diferença cultural têm tanta possibilidade de serem consensuais quanto conflituosos; podem confundir nossas definições de tradição e modernidade, realinhar as fronteiras habituais entre o público e o privado, o alto e o baixo, assim como desafiar as expectativas normativas de desenvolvimento e progresso. (BHABHA, 1998, p. 21).

A presença do imigrante acidental, que veio para Juiz de Fora trabalhar e por aqui ficou, estabelecendo laços de pertencimento e ajudando a formatar a identidade da cidade, foi a questão principal da matéria. A abordagem, como 
costuma ocorrer nos momentos de comemoração de uma nação ou uma cidade, reverberava as contribuições positivas que cada grupo legou à identidade formada pela mescla das que ali se encontraram.

A quarta e última reportagem da série especial de aniversário foi ao ar no MGTV $2^{a}$ edição de sábado, dia 30 de maio, chamando para uma reflexão: "Juiz de Fora, 159 anos: Como conciliar qualidade de vida e crescimento econômico?” (MGTV 2a edição, 30/05/2009). A matéria apontava os benefícios e os problemas de Juiz de Fora para continuar a ser considerada a principal cidade da região da Zona da Mata Mineira:

Uma cidade bem localizada. Que surgiu às margens do Rio Paraibuna. Ganhou notoriedade, cresceu e hoje enfrenta um dilema: como manter a qualidade de vida da população? Mas, para manter o título de maior cidade da região, Juiz de Fora precisa melhorar sua saúde e qualificar ainda mais seus moradores. Aí sim, a Princesinha de Minas ou a Manchester Mineira vai voltar a brilhar diante da imensidão que é Minas Gerais (MGTV 2a edição, 30/05/2009).

Mesmo diante dos desafios, contudo, a reportagem ainda mostrava exemplos e personagens que colocam Juiz de Fora como cidade polo na educação e na saúde, com boas opções de cultura e qualidade de vida: "Qualidade de vida alta. Juiz de Fora está acima de países como Cuba e Rússia no índice de desenvolvimento humano, que leva em conta a renda per capita, educação e longevidade" (MGTV 2a edição, 30/05/2009). Revelava-se, neste específico momento, uma cidade com muitas qualidades e poucos problemas. A matéria, com três minutos e cinco segundos de produção, encerrava o telejornal com imagens de símbolos de Juiz de Fora.

Em resumo, o tom celebratório esteve muito presente nas reportagens da série, que mostraram uma Juiz de Fora multifacetada e, paradoxalmente, ainda una e homogênea nestas muitas facetas - tanto é assim que é possível falar em juizforaneidade. Neste sentido, a cobertura demonstra como as identidades como comunidades imaginadas a gerarem o sentimento de pertença - articulam a construção simbólica da unidade a partir da diversidade. Como sustenta Stuart Hall:

Assim, a identidade é realmente algo formado, ao longo do tempo, através de processos inconscientes, e não algo inato, existente na consciência no momento do nascimento. Existe sempre algo "imaginário" ou fantasiado sobre sua unidade. Ela permanece sempre incompleta, está sempre "em processo", sempre "sendo formada". (HALL, 2000, p. 38).

\section{Considerações finais}

Nas sociedades contemporâneas, os meios de comunicação ocupam um papel central. É por meio deles que a maioria dos cidadãos tem acesso às infor- 
mações sobre o que se passa no mundo e na cidade. Dentre os veículos de comunicação, a televisão em especial tem uma função importante na formação do imaginário urbano, construindo laços de pertencimento entre os habitantes e os espaços onde vivem. É certo que os telespectadores não são passivos diante do que veem na TV, mas é igualmente razoável afirmar que alguns deles dependem excessivamente da TV como única fonte informativa.

Deste modo, apesar de os cidadãos viverem na cidade, andarem em suas ruas, perceberem-na concretamente todos os dias, muitas das representações que dela fazem não decorrem de suas experiências vivenciadas - nutrem-se do imaginário sobre ela consolidado, das narrativas que baseiam os sentidos sociais sobre ela produzidos e partilhados no espaço público. O que implica dizer que a representação da cidade pela mídia - produzida a partir dos enquadramentos dados a ela cotidianamente - tem profundos impactos nas narrativas que os habitantes de uma localidade fazem sobre si mesmos.

Ou seja, os meios ajudam a construir ou reforçar identidades. Toda vez que os registros jornalísticos resgatam a história e a memória da cidade, fazemno por meio de escolhas sobre o que será lembrado e o que será esquecido. Segundo Enne, "existe, portanto, uma intensa relação entre a memória como processo coletivo de construção do passado a partir de demandas do presente e a conferência de identidades sociais para aqueles que estão envolvidos em tal processo" (ENNE, 2004, p.105).

A televisão recria o imaginário urbano a partir do momento em que ajuda a ordenar o espaço público, a qualificar alguns lugares e a desqualificar outros, a dar visibilidade a alguns assuntos e a deixar outros no esquecimento. Logo, a cidade que é mostrada nos telejornais não é mais do que um recorte dentre muitas cidades possíveis.

Sendo os discursos que circulam pelos meios de comunicação variáveis fundamentais para a formação da opinião pública (sobretudo daqueles setores que só têm acesso à informação mediada), o noticiário veiculado por eles influencia em alguma medida a percepção do mundo de parcelas significativas da sociedade. A imagem urbana será ratificada ou contestada a partir da cidade veiculada pela mídia.

Consequentemente, o discurso adotado pelas matérias constrói relações identitárias, cria laços de pertencimento, faz com que as pessoas se reconheçam (ou não) naquela cidade. No caso específico da série de matérias especiais sobre o aniversário de 159 anos de Juiz de Fora-MG veiculadas nos MGTVs $1^{a}$ e $2^{a}$ edições da TV Panorama, elas reforçam certos traços de um discurso mítico sobre a juizforaneidade.

Segundo Musse, "o imaginário urbano é constituído das muitas narrativas sobre a cidade, portanto, a cidade é fábula, não existe uma única cidade 'real'” (MUSSE, 2006). A Juiz de Fora construída pelas reportagens da TV Panorama apresenta-se assentada na ideia de que a cidade é fruto do encontro do tradicional com o moderno (a configurar uma posição nova, intermediária); dos estrangeiros que, para cá vindo, amalgamaram-se (a superar as alteridades e constituir uma nova identidade); das especificidades de seu passado pujante - que coloca desafios econômicos para o presente, mas ainda se manifesta por meio de traços de significativo avanço social.

Não se trata aqui de avaliar o quanto essa cidade existe efetivamente ou não. 
Dependendo de quais recortes - ressalte-se, legítimos - sejam feitos, essa narrativa pode sim corresponder à Juiz de Fora composta de ruas, praças e construções (e, fundamentalmente, das pessoas que nela habitam). Trata-se apenas da necessidade de lutar para que estas narrativas não sejam instrumentos de ocultação do fato de que as identidades são sempre múltiplas e cambiantes. Como observa Augé, "certos lugares só existem pelas palavras que os evocam, não-lugares nesse sentido ou, antes, lugares imaginários, utopias banais, clichês" (AUGÉ, 1994, p.88).

A questão é observar que, apesar de legítima, esta narrativa supõe uma unidade que a cidade não tem, nem nunca teve. É importante notar que, ao falar do que Juiz de Fora supostamente foi ou é, a cobertura televisiva nutre-se de discursos já feitos e, ao refazê-los, realimenta projeções identitárias. Como numa profecia auto-realizável, ao dizer-se na televisão algo de Juiz de Fora e dos juizforanos, criam-se especiais condições para que estes discursos sejam internalizados e, por vezes, incorporados ao senso comum sem a devida criticidade. $\mathrm{E}$, sem criticidade, a memória não ilumina adequadamente o presente, para reinventá-lo.

\section{Referências bibliográficas}

ABRAMO, Perseu. Padrões de manipulação na grande imprensa. São Paulo: Editora Fundação Perseu Abramo, 1 ed., 2003.

AUGÉ. Marc. Não-lugares: introdução a uma antropologia da supermodernidade. Trad. Maria Lúcia Pereira. 3. ed. Campinas, SP: Papirus, 1994.

BERGER, P. T., LUCKMANN, T. A construção social da realidade. 12. ed. Petrópolis: Vozes, 1995.

BHABHA, Homi K. O local da cultura. Tradução de Myriam Ávila, Eliana Lourenço de Lima Reis, Gláucia Renate Gonçalves. Belo Horizonte. Ed. UFMG, 1998.

CALVINO, Ítalo. As cidades invisíveis. Tradução: Diogo Mainardi. São Paulo, Companhia das Letras, 1990.

CAIAFA, Janice. Aventura das cidades - ensaios e etnografias. Rio de Janeiro: Ed. FGV, 2007.

GUARESCHI. Neuza Maria de F. A mídia e a produção de modos de ser da adolescência. PPGP / PUCRS. Revista FAMECOS. Porto Alegre, $\mathrm{n}^{\circ}$ 30, agosto/2006, quadrimestral.

HALL, Stuart. Quem precisa da Identidade? In: SILVA, Tomás Tadeu (Org.). Identidade e Diferença: a perspectiva dos estudos culturais. Petrópolis: Vozes, 2000. p. 103-133.

. Da diáspora: identidades e mediações culturais. Organização: Liv Sovik. Tradução: Adelaine La Guardiã Resende. Belo Horizonte. Editora UFMG. Brasília. Representação da UNESCO no Brasil, 2003.

COUTINHO, Iluska; MARTINS, Simone Teixeira. Identidade no Telejornalismo Local: a construção de laços de pertencimento entre a TV Alterosa Juiz de Fora e o seu público. In: Colóquio Internacional Televisão e Realidade, 2008, Salvador/BA. Colóquio Internacional Televisão e Realidade, 2008. MGTV $1^{a}$ EDIÇÃO, TV Panorama, Juiz de Fora-MG, 28/05/2009. 
MGTV $1^{a}$ EDIÇÃO, TV Panorama, Juiz de Fora-MG, 29/05/2009.

MGTV $1^{\text {a }}$ EDIÇÃO, TV Panorama, Juiz de Fora-MG, 30/05/2009.

MGTV $2^{a}$ EDIÇÃO, TV Panorama, Juiz de Fora-MG, 30/05/2009.

MUSSE, Christina Ferraz. Imprensa, cultura e imaginário urbano: exercício de memória sobre os anos 60/70 em Juiz de Fora. 1. ed. São Paulo: Nankin, 2008. v. 01.

OLIVEIRA, Mônica Ribeiro de. Juiz de Fora: vivendo a história. Juiz de Fora: Núcleo de História Regional da UFJF / Editora da UFJF, 1994. 121p.

SILVA, Adriana Fernandes da. Identidade e representações no telejornalismo regional: o caso da TV Tem Bauru. UNESP. In: Intercom - Sociedade Brasileira de Estudos Interdisciplinares da Comunicação - XXVIII Congresso Brasileiro de Ciências da Comunicação - Uerj - 5 a 9 de setembro de 2005. SILVA, Tomás Tadeu. A produção social da identidade e da diferença. In: . (Org.). Identidade e Diferença: a perspectiva dos estudos culturais. Petrópolis: Vozes, 2000. p.73-102.

WEBER, Maria Helena. A cidade traída: os recortes da mídia e do governo. XV Encontro Anual da COMPÓS, UNESP-Bauru, junho de 2006.

WOODWARD, Kathryn. Identidade e diferença: uma introdução teórica e conceitual. In SILVA, Tomás Tadeu (Org.). Identidade e Diferença: a perspectiva dos estudos culturais. Petrópolis: Vozes, 2000. p.7-72. 